\title{
HOW SERIOUS IS THREAT OF RADIOLOGICAL TERRORISM?
}

\author{
Pavel Kuna' ${ }^{1}$ Zdeněk Hon ${ }^{3}$, Jiři Patočka ${ }^{2,3}$
}

Institute of Applied Economical Studies, Prague, Czech Republic: Department of Health and Social Studies ${ }^{1}$, Department of Technical and Environmental Sciences²; University of South Bohemia, České Budějovice, Faculty of Health and Social Studies, Czech Republic: Department of Radiology and Toxicology ${ }^{3}$

Summary: Radiological terrorism (radioterrorism) is the deliberate use of radiological weapons. These weapons use radioactive materials to disperse and emit ionizing radiation. There are two classes of radiological weapons - radiological dispersal devices (RDD) and radiation emission devices (RED). These weapons would no cause massive numbers of dead. In most radiological attack scenarios, only few people may die immediately or shortly after exposure to the ionizing radiation. Nevertheless, many people could develop cancer within several years to decade after the radiological weapon attack. Such attack might spur panic and result in high economic costs because of the need for decontamination and possible tearing down and reconstruction of contaminated structures. Thus, radiological weapons may be considered rather weapons of mass disruption than weapons threating of human life.

Key words: Radiological terrorism; Dirty bomb; Risk; Contamination; Environment

\section{Introduction}

The attacks of September 11th showed that terrorist groups are capable of causing mass casualties and are prepared to do so. During the past several years, humanity concern about the use of radioactive material by terrorists as a radiological weapon has increased considerably. The threat of radiological terrorism is not new (28), but it has received renewed news media and public attention. Most of Americans as well as peoples in other countries are satisfied that a radiological terrorist attack on the United States is a possible. They believe that construct like this device capable to disperse radioactive material is easy. Such device is known as „dirty bomb“. It is an unfamiliar and unconventional form of weapon, and this lack of knowledge has only served to increase public fear. To decrease our vulnerability to this type of threat, the medical community should have a basic understanding of radiation hazards and their medical management (19). Learning more about the probability, effects, and consequences of such an attack will help to calm fear and lessen panic if a radiological attack actually occurs (25).

\section{Radiological terrorism}

As terrorism has become a daily topic of news headlines, the looming threat of radiological terrorism has become more apparent. Radiological terrorism is more probable than nuclear terrorism $(7,15)$. Radiological terrorism is the de- liberate use of radioactive material to cause destruction, contamination, and injury (18). Terrorists can employ a variety of active and passive methods to disseminate or expose people to the radioactive material. Passive methods are any that place unshielded radioactive material in a location so as to expose people to the source, with the intention of causing harm. Active methods include dilution of an isotope in a water supply, use of a remote control devices, or missiles. The most widely-known dissemination method is through explosives, commonly called a "dirty bomb" (23). Dirty bomb is only one type of radiological weapon (9). Other kind of radiological weapons are different sorts of radiation emission devices (RED). Terrorists might try placing a RED in a crowded location in heavily populated areas such as a busy train station.

Concerns about the threat of radiological terrorism revolve around the ease with which radioactive materials can be acquired, either legally or through theft, from industrial or medical sources. A radiological weapon or radiological dispersion device (RDD) is any weapon that is designed to spread radioactive material with the intent to kill, and cause disruption upon a city or nation (30).

\section{Dirty bomb}

The RDD primarily known as a dirty bomb is not a true nuclear weapon and does not yield the same destructive power. It uses conventional explosives to spread radioactive material, most commonly the spent fuels from nuclear 
power plants or radioactive medical waste (2). The possibility of the detonation of dirty bomb has been the focus of much of this apprehension. Press reports of illicit traficking in radioactive material, Web chat attributed to terrorist groups, and the discovery of primitive drawings of dirty bombs in the possession of international terrorist groups have heightened this concern. International experts believe that crude devices could easily be constructed (27).

At all events, public statements of experts increasingly warn of a growing threat of radiological terrorism that is in need of urgent attention. In response, most of governments have intensified its efforts to improve control of radioactive material. The loss of control could constitute serious threat. Therefore were accepted security programs to improve security at facilities where radioactive material is located in a number of countries and to intercept radioactive material that has entered the international black market. A dirty bomb combines conventional explosives, such as dynamite, with radioactive materials packed around the explosive core. The idea is to spread radioactive material into the area around the explosion and frighten people. Indeed, the main

Tab. 1: Commercially Available Radioisotopes which Pose the Greatest Security Risk.

\begin{tabular}{|c|c|}
\hline Element & Half-life \\
\hline Americium-241 & 433 years \\
\hline Californium-252 & 2.7 years \\
\hline Cesium-137 & 30.1 years \\
\hline Cobalt-60 & 5.3 years \\
\hline Iridium-192 & 74 days \\
\hline Plutonium-238 & 88 years \\
\hline Radium-226 & 1600 years \\
\hline Strontium-90 & 28.6 years \\
\hline
\end{tabular}

Tab. 2: High-Risk Sources of Radioisotopes. damage from a dirty bomb would be associated with the blast itself, while contamination with radioactive materials to people or the environment is expected to cause only limited harm (22).

\section{Contamination of environment}

Contamination of drinking water or food supplies with highly radioactive materials is one of way how threaten civilian people (17). Such terroristic attack may be attend by the destruction of critical infrastructure with food shortages and resultant malnutrition leading to the foodborne and waterborne illness (26). Nevertheless, it appears that chemical or biological terrorist action is simplex for terrorists (10).

\section{Radioactive material}

The most likely radioactive materials to be used are cobalt-60, strontium-90, cesium-137 and americium-241, which are unfortunately often poorly protected and readily available from military, medical, academic, research, and industrial sources. As an example, cobalt-60 is used in food irradiation or in medical material sterilize, while americium is used in smoke detectors and oil exploration. The survey of commercially available radioisotopes which pose the greates security risk are summarized in Table 1. These materials are already believed to be in the possession of major international terrorist groups. Military-grade plutonium and uranium would be more deadly, but are significantly harder to obtain, handle and safely transport. Also nuclear fuel from commercial reactors is usually very highly radioactive, it would appear to offer an ideal type of material for a radiological weapon. Further information about high-risk sources of all these radioisotopes are given in Table 2.

\begin{tabular}{|l|c|c|}
\hline Practice or Application & Radioisotope & Radioactivity (Curies) \\
\hline Thermoelectric generators & Strontium-90 & 2800 \\
\hline Sterilization and food irradiators & Plutonium-238 & Up to 4000000 \\
& Cobalt-60 & Up to 4000000 \\
\hline Single-beam teletherapy & Cesium-137 & 4000 \\
& Cobalt-60 & 700 \\
\hline Multi-beam teletherapy & Cesium-137 & 600 \\
\hline Industrial radiography & Cobalt-60 & 100 \\
\hline Calibration & Cobalt-60 & 20 \\
& Iridium-192 & 60 \\
& Cobalt-60 & 10 \\
\hline High/Medium-dose rate brachytherapie & Cesium-137 & 10 \\
& Americium-241 & 3 \\
\hline Well logging & Kobalt-60 & 6 \\
\hline Level and conveyor gauges & Cesium-137 & 2 \\
& Iridium-192 & 20 \\
\hline
\end{tabular}


As pointed out Charles D. Ferguson and his co-workers (2003) from Washington, DC Office of the Monterey Institute's Center for Nonproliferation Studies, commercial radioactive sources are not cushioned in all cases and represent certain security risk. Domestic regulatory controls in the states of the former Soviet Union and in a number of developing countries are very often incontinent in keeping of security. Other countries are in no better position. As reported John Bolton at the IAEA Conference on Nuclear and Radiation Safety in London, September 30, 2002, only in the United States alone, 375 radioactive sources on average are lost or stolen annually. Radioactive material can get to trespassers and misused for terroristic attack. More control is vital (31).

\section{Medical effects}

Medical effects of nuclear explosions and other forms of radiation exposure, assessment of radiation dose, triage of victims, definitive treatment of radiation and combinedinjury casualties, and planning for emergency services after a terrorist attack involving a nuclear device. It is assumed that direct radiation damage after radiological weapon use won't be weighty. After explosion of dirty bomb, mechanical-injuries will be meaningly than radiological damage, nevertheless in combined-injury these damages may be important in future.

\section{Decontamination}

The most common contaminants will emit primarily alpha particles and gamma radiation, with minimal beta exposure. Gamma-radiation emitters may cause whole-body irradiation. Beta emitters when left on the skin can produce serious burns and scarring. Alpha radiation does not penetrate the epithelium. Most of the time, the simple removal of outer clothing and shoes will reduce contamination by $90 \%$. External contamination of the skin and hair is from particulate matter that can be washed off. If practical, the clothing and effluent from washing should be sequestered and disposed of properly. Internal contamination can occur when unprotected individuals inhale, ingest, or are wounded by radioactive material.

Decontamination is a method for removing a wide variety of radioactive contaminants from a contaminated surface including human body surface. Decontamination methods are mechanical or chemical. Personnel decontamination methods differ from those used for materials primarily because of the possibilities of injury to the subject. Soap and water normally remove more than $99 \%$ of the contaminants. If it is necessary to remove the remainder, chemical methods which remove the outer layers of skin can be used. These chemicals, such as citric acid, potassium permanganate, and sodium bisulfite, should be used with caution and preferably under medical supervision because of the risk of injury to the skin surface. It is very difficult to remove radioactive material once it is fixed inside the body.

\section{General treatment}

The threat of radiologic terrorism is increasing, yet many physicians are unfamiliar with basic treatment principles for radiologic casualties. Patients may present for care after a covert radiation exposure, requiring an elevated level of suspicion by the physician. Traditional medical and surgical triage criteria should always take precedence over radiation exposure management or decontamination (11). Physicians, hospitals, and other health care facilities will assume the responsibility for aiding individuals injured by a terrorist act involving radioactive material (29).

As a general medical problem, radionuclide intakes that may cause significant health effects are uncommon events. The medical aspects of such an accident are only one part of the management, and a professional team approach is required (3). Absorption of ingested radioactive material depends on the solubility and chemical makeup of the contaminant. For example, cesium is rapidly absorbed; cobalt, radium, and strontium are not. The target organ for ingested radionuclides that pass unchanged in the feces is the lower gastrointestinal tract. Gastric lavage and emetics can help empty the stomach promptly, while purgatives, laxatives, and enemas can reduce radioactive materials in the colon. Ion exchange resins limit gastrointestinal uptake of ingested or inhaled radionuclides. Prussian blue (ferric ferrocyanid) and alginates have been used in humans to accelerate fecal excretion of cesium- 137.

Inhaled particles less than 5 microns in size will end up in the alveolar area, while the mucociliary apparatus will clear larger particles. Soluble particles are then directly absorbed into the blood stream or moved into the lymphatic system. Insoluble particles, until cleared, will continue to irradiate surrounding tissues. In the alveoli, the localized inflammatory response can produce fibrosis and scarring.

The skin is impermeable to most radionuclides, but wounds and burns allow particulate contamination to bypass the epithelium. Because of this, all contaminated wounds must be meticulously cleaned and debrided.

Once absorbed, a radionuclide crosses capillary membranes through passive and active diffusion and is distributed throughout the body. Organ metabolism, the ease of chemical transport, and the affinity of the radionuclide for chemicals within the organ determine the rate of distribution, with the liver, kidney, adipose tissue, and bone having greater capacities for binding radionuclides because of their high protein and lipid makeup. Heavy metal poisoning is also a potential threat depending upon the isotope used. Chelation agents should be administered as needed. Calcium edetate (EDTA) is used primarily to treat lead poisoning but must be used with extreme caution in patients with preexisting renal disease. Diethylenetriaminepentaacetic acid (DTPA) is more effective in removing many of 
the heavy-metal, multivalent radionuclides. Dimercaprol forms stable chelates with mercury, lead, arsenic, gold, bismuth, chromium, and nickel and may be considered for the treatment of internal contamination with radioisotopes of these elements. Another consideration is penicillamine, which chelates copper, iron, mercury, lead, gold, and possibly other heavy metals.

\section{Specific treatment}

Specific priorities and sequencing are necessary in medically managing a radionuclide intake or inhalation. As soon as is reasonably practical, promptly remove the victim(s) from further radionuclide, radiation field, or chemical exposure (1). Post-irradiation approaches to treatment of radiation injuries in the context of radiological terrorism and radiation accidens are discussed at large in the review of Moulder (2004).

Americium-241. DTPA or EDTA chelation in the first 24 to 48 hours following pulmonary exposure is effective.

Cesium-137. Prussian blue and ion exchange resins are useful. If early after ingestion, use lavage and purgatives.

Cobalt-60. Gastric lavage and purgatives are advised for ingestions. Severe cases can be treated by chelation with penicillamine.

Phosphorus-32. Treatment includes lavage, aluminum hydroxide, and oral phosphates.

Radium-226. After ingestion, immediately lavage with $10 \%$ magnesium sulfate followed by saline and magnesium purgatives. Ammonium chloride may increase fecal elimination.

Strontium-90. Immediately after ingestion, oral administration of aluminum phosphate can decrease absorption by as much as $85 \%$. Administration of stable strontium can competitively inhibit the metabolism and increase the excretion of strontium-90. Large doses of calcium and acidification of the urine with ammonium chloride will also increase excretion.

\section{Prophylaxis}

Sulphydryl radioprotectors are the best radioprotectors known today against acute radiation sickness. Their use encounters two great difficulties: their toxicity and the short period during which they are active (20). Probably the most effective is amifostine (gammaphos, WR-2721) against whole body gamma exposures $(12,16)$. The radioprotective effects of WR-2721 or cystamine were not significant before lehal effect of fission neutron irradiation animals $(13,14)$. Their prophylactic use at radiological terroristic attack is illusory. The chemical radioprotectors cannot modulate radiation injury when given after irradiation. But the combination of radioprotectors (WR-2721 or cystamine) with a complex antibiotic and vitamines treatment were able to increase survival of whole body gamma irradiated dogs with a lethal dose of $3 \mathrm{~Gy}$ of $48{ }^{60} \mathrm{Co}$ gamma sources of Chisobox significantly (16). Kalium iodide tablets only occure high prophylactic effect on thyroid gland and moderate therapeutic ability against radioactive iodine contamination.

\section{Psychological effect}

Most people fear a radiological threat even more than a conventional explosion due both to their inability to perceive the presence of radiation with the ordinary human senses and to concerns about perceived long-lasting radiation effects. Studies of radiological accidents have found that for every actually contaminated casualty, there may be as many as 500 people who are concerned, eager to be screened for contamination, sometimes panicked, and showing psychosomatic reactions mimicking actual radiation effects (24). Such responses would likely be common in any future radiological accident or terrorist attack.

Radiological terrorism, as well as terrorism in any form, can be psychologically devasting. Psychological consequences include an array of emotional, behavioral, and cognitive reactions. People may experience insomnia, fear, anxiety, vulnerability, anger, and a minority will develop psychiatric illnesses such as posttraumatic stress disorder or depression. Management of the psychological consequences of terrorism will require a range of interventions at multiple levels involving a variety of service providers. Interventions are needed for the pre-event, event, and post-event phases of a terrorist attack and will have to address affected individuals and populations (4).

In the connection of number of casualties and in situations with limited medical resources, be they personnel, equipment, or time, clinicians use "triage" to determine which patients receive treatment. What type of treatment a patient receives depends on the triage "lottery" rules in place. Although these rules for sorting patients and distributing resources are standardized for most situations, they must be somewhat altered after overwhelming, nonstandard disasters, as are just radiological terrorist attacks (8).

\section{Bioterrorism contra radiological terrorism (radioterrorism)}

The antiterrorism and disaster planning communities often speak of the high potential for bioterrorism and possible potential for radioterrorism, specifically the explosion of a fission device on US soil. Information gained from an epidemiologist's work in the national and international scene suggest that bioterrorism is far less likely to be a major threat, that has been over-emphasized at the state level due to warnings from Homeland Security, and that Homeland Security itself appears biased toward bioterrorism of late with very little available rational basis (6).

\section{Conclusions}

The International Atomic Energy Agency is concerned that terrorists could carry out potential attacks by targeting 
nuclear facilities using bombs or hijacked commercial airliners, or by dispersal of radioactive materials with or without the use of conventional explosive devices. The radiation dispersal device, so called dirty bomb, contains radioactive material in addition to conventional explosives, with the intent to disperse the material and cause contamination and radiation. Possible sources of radioactive materials include spent reactor fuel, commercially produced and purchased radioisotopes, and low level radioactive waste

from laboratory and medical procedures. There are also another scenarios of radioterrorism, but these are less probable (32). For many, the thought of terrorists detonating a dirty bomb is frightening. However, the radiation health risks from such an occurrence are small (23).

\section{References}

1. Barnett DJ, Parker CL, Blodgett DW, Wierzba RK, Links JM. Understanding radiologic and nuclear terrorism as publuc health threats: Preparedness and response perspectives. J Nucl Med 2006;47:1653-61.

2. Bechtel D. Radioactive Dispersion Devices (RDD): What are the Odds? Techno Society $2007 ; 1-2: 1-7$

3. Breitenstein $\mathrm{BD}$. The medical management of uniinternational radionuclide intakes. Rad Protect Dosimetry 2003;104:495-7.

4. Butler AS, Panzer AM, Goldfrank LR (Eds). Preparing for the Psychologica Consequences of Terrorism. A Public Health Strategy. National Acad. Press, Washington DC, 2003. 184 p. ISBN: 978-0-309-08953-1.

5. Ferguso CD, Kazi T, Perera J. Commercial radioactive sources: surveying the security risk. Disarmament Forum 2003;23-28. (http://www.unidir.org/pdf/articles/pdf-art1909.pdf).

6. Goffman TE. Bioterrorism versus radiological terrorism: notes from a bio/nuclea epidemiologist. Am J Disaster Med 2009;4:9-14.

7. Hon Z, Kaňková J, Patočka J. Potenciální nástroje CBRN terorismu. Krízový manažment 2008; 7:52-7.

8. Iserson $\mathrm{KV}$, Pesik N. Ethical resource distribution after biological, chemical, or radiological terrorism. Cambridge Quart Healthcare Ethics 2003;12:455-65.

9. Kaňková J. Dirty bomb (Article in Czech). Kontakt 2006;8:128-32.

10. Khan AS, Swerdlow DL, Juranek DD. Orecautions aganinst biological and chemical terrorism directed at food and water supplies. Public Health Rep 2001;116 3-14.

11. Koenig KL, Goans RE, Hatchett RJ, Mettler FA, Schumacher TA, Noji EK Jarrett DG. Medical treatment of radiological casualties: Current concepts. Ann Emerg Med 2005;45:643-52.
12. Kuna P. Chemical radioprotective substances: The past, present and the future (Article in Czech). Kontakt 2006;8:112-22.

13. Kuna P, Dostál M, Neruda O., et al. Radioprotective effects of amifostine (WR 2721 ) or cystamine on radiation damage and its repair in rats whole body exposed to fission neutrons. Acta Medica (Hradec Kralove) 2004;47:19-23.

14. Kuna P, Dostál M, Neruda O., et al. Acute toxicity and radioprotective effects of amifostine (WR-2721) or cystamine in single whole body fission neutrons irradiated rats. J Appl Biomed 2004a;2:43-9.

15. Kuna P, Neruda O, Navrátil L, Matzner J, Žišková R. Nuclear terrorism. J Appl Biomed 2003;1:55-9.

16. Kuna P, Navrátil L, Singer J. Amifostine (WR-2721) as a radioprotector for the emergency workers. Current problems of radiation reserch. Proc. of the $35^{\text {th }}$ Ann Meet. of the Europ. Radiat. Res. Soc., 2006. National Academy of Sciences of Ukraine, Eds Grodzinsky D., Dmitriev A., Kyiv, Ukraine 2007:211-223. ISBN: 966-306-128-4.

17. Leikin JB, McFee RB, Walter FG, Edsall K. A primer for nuclear terrorism. Disese-a-Month 2003;49:485-516

18. Levett J. Radiological terrorism scenarios. Prehosp Disaster Med 2007;22:346.

19. McCurley MC, Miller CW, Tucker FE, Guinn A, Donnelly E, Ansari A, Holcombe M, Nemhauser JB, Whitcomb RC Jr. Educating medical staff about responding to a radiological or nuclear emergency. Health Phys 2009;96, Suppl 2:S50-4.

20. Maisin JR. Bacq and Alexander Award lecture chemical radioprotection: past, present and future prospects. Int J Radiation Biol 1998;73:1362-95.

21. Moulder JE. Post-irradiation approaches to tratment of radiation injuries in the context of radiological terrorism and radiation accidents: a review. Int $\mathbf{J}$ Radiation Biol 2004:80:3-10.

22. Oumeish OY. Nuclear terrorism: health and environmental hazards and threats from ionizing and nuclear radiation. Clin Dermatol. 2002;20:330-5.

23. Ring JP. Radiation risks and dirty bombs. Health Phys 2004;86, Suppl 2:S42-7.

24. Salter CA. Psychological effects of nuclear and radiological warfare. Mil Med 2001;166:17-8

25. Sheppard B, Rubin GJ, Wardman JK, Wessely S. Terrorism and dispelling the myth of a panic prone public. J Public Health Policy 2006;27:219-45.

26. Sidel VW, Levy BS, Slutzman JE. Prevention of war and its environmental consequences. Handbook of Environmental Chemistry, Springer-Verlag Berlin, Heidelberg 2009;21-39.

27. Sutton V, Bromley DA. Understanding technologies of terror. Tchnol Society 2005;27:263-85.

28. Timins JK, Lipoti JA. Radiological terrorism. N J Med 2003;100:14-21.

29. Waselenko JK, MacVittie TJ, Blekely WF et al. Medical management of the acute radiation syndrome: Recommendations of the strategic national stockpile radiation working group. Ann Internal Med 2005;140:1037-51.

30. Willis D, Coleman EA. The dirty bomb: management of victims of radiological weapons. Medsurg Nurs 2003;12:397-401.

31. Wood WD, Robinson DM. International Approaches to Securing Radioactive Sources Against Terrorism. NATO Science for Peace and Security Series - C. Environmental Security. Springer-Verlag, Berlin, Heidelberg 2008. 230 p. ISBN 1402092717.

32. Yehezkelli Y, Dushnitsky T, Hourvitz A. Radiation terrorism - the medical challenge. IMAJ 2004;4:530-4

Received: 04/07/2009.

Accepted: 14/09/2009.

\section{Corresponding author:}

Prof. MUDr. Pavel Kuna, DrSc., Patrného 191, 55101 Jaroměř, Czech Republic; e-mail: kuna.pavel@gmail.com 